\title{
LUXIÉRNAGA
}

Christopher Felipe Aguayo Sánchez 


\section{El pensamiento de Marx como modelo para la filosofía práctica}

\section{Introducción}

Mucho se ha escrito sobre las diversas teorías filosóficas que ayudan al hombre en su conocimiento y enriquecen su sabiduría de forma excepcional, aquí ahora, analizaremos parte de este pensamiento filosófico, para poder aplicarlo en la acción humana, es decir, que la filosofía no sólo permanezca en la mente, sino que, pueda ser aplicable para la vida cotidiana, de cada hombre y sus necesidades. Actualmente se han retomado diversas ramas de la filosofía que convierten al filósofo en un asesor, que puede orientar a diferentes hombres en sus intereses personales, de tal manera que se demuestra que ésta ideología puede ser puesta en el quehacer humano. Ahora bien, no es solo en la actualidad que se ha querido hacer filosofía práctica, sino que, en el siglo XIX, Karl Marx, tuvo una enorme influencia en la historia contemporánea de Europa, pues fue un siglo lleno de conflictos y revoluciones en las que el pensamiento Marxista participó por medio de la filosofía. En el presente trabajo intentaremos demostrar la teoría más importante de Karl Marx, desde sus inicios hegelianos, y veremos la idea del comunismo marxista, para un nuevo sistema económico del México actual.

\section{Karl Marx}

Karl Marx nace el 5 de mayo de I8I8 en Prusia, lo que es hoy Alemania. Fue el tercer hijo de nueve y bautizado en una iglesia luterana, aunque abandonaría la religión y se convertiría en un ateo. El primer profesor de Marx fue su padre, quien era abogado, después ingresó a una escuela con tendencia liberal y humanista, lugar en donde empezarían sus intereses por ambas corrientes. En I830 prosiguió sus estudios en la universidad de Bonn, donde deseaba estudiar filosofía y literatura, pero, por la presión de su padre, terminó por estudiar derecho; al tener un rendimiento bajo en la 
licenciatura, se trasladó a Berlín, en donde amplió especialmente sus conocimientos e intereses sobre la historia y la filosofía. Su primera tesis, Diferencias de la filosofia de la naturaleza en Demócrito y Epicuro, la desarrolló en la universidad de Jena y fue publicada en I84I. En esta tesis, Marx, comenzaría a descubrir los primeros pasos para su crítica materialista de la religión y empezaría a encontrarse con temas de interés general de una sociedad oprimida por los altos mandos del mismo pueblo. ${ }^{1}$

En enero de 1866, Marx comienza la redacción de El capital. Esta obra consta de tres volúmenes, aunque Marx sólo escribió el primero y su amigo F. Engels la completaría. En esta obra, Marx muestra que la producción de la clase burguesa no es sólo de mercancías, sino que también genera plusvalía, es decir, por la parte vendida de las mercancías el burgués obtiene una expresión monetaria del valor que el trabajador asalariado crea por encima del valor de su fuerza de trabajo, esto genera capital, lo que hace una diferencia de clases sociales, especialmente en la economía de cada individuo de la sociedad, es decir, el trabajador es ajeno a la riqueza obtenida y a las mercancías que está elaborando, el único beneficiario es el burgués. ${ }^{2}$

Marx hace referencia en su obra a que el capital puede ser derrumbado por la misma fuerza que lo sostiene, es decir el proletario. Por otra parte, hace una crítica a la economía política desde sus orígenes, en donde analiza cómo evoluciona la historia de la humanidad dependiendo de la época en la que se está. En dicha obra se puede analizar la economía, la política, la historia y la filosofía, también encontramos un Marx con ideas revolucionarias para crear justicia para los oprimidos.

\section{Nacimiento del pensamiento de Karl Marx desde Hegel}

Hegel nace el 27 de agosto de 1770 en Stuttgart, actual Alemania, durante sus estudios, propone que la filosofía debe ser entendida, y tratada, como una ciencia, pues expresa esencialmente que el universo está bajo un constante movimiento, y que

\footnotetext{
1 Fernández, V., Redhistoria, (2 de Julio de 2018). Recuperado el 30 de Agosto de 2019, de https://redhistoria.com/biografia-de-karl-marx/., p. 143.

${ }^{2}$ Ibid., p. 145.
} 
esto es necesario para que puedan surgir nuevos movimientos, comprueba que todo está en movimiento y que cambia, que nada está aislado, que todo depende de todo, porque es un proceso de desarrollo dialéctico, sostenía que Hegel era un idealista y para Hegel, primero estaba el pensamiento, después la materia, y sustentaba que los cambios en el espíritu son los que hacen los cambios en la materia. ${ }^{3}$

Podemos entender entonces, a la dialéctica Hegeliana como movimiento, donde todo cambia, todo se mueve, es decir, todo nace y caduca, el hombre, la naturaleza, los procesos sociales, de tal manera que podemos decir que la dialéctica, al observar al hombre y su entorno, responde a la realidad, observa los movimientos que se efectúan dentro de ella, por ejemplo, la sociedad no es inmóvil, pues existen diversas facetas en las que la historia del hombre se ha proporcionado diversos cambios, pues en su historia hubo esclavismo, después feudalismo y por último capitalismo, esto solo por mencionar un ejemplo práctico y si lo pensamos desde la postura Hegeliana, los sentimientos, lo que es simpatía, puede convertirse en amor y después en odio, demostrando así, el movimiento dialéctico. ${ }^{4}$

Marx nos hereda diversos pensamientos, que hasta la fecha siguen vigentes, algunos de los principales es su forma de comprender el entorno social de una manera práctica, podemos decir que muchos filósofos han tratado de explicar el mundo, sin embargo, esto sólo se queda en la teoría, Marx no sólo trataba de explicar su pensamiento, sino que, con este mismo, intentaba cambiar el mundo. Una de sus propuestas principales es la lógica dialéctica, que se basa fundamentalmente en la historia de las sociedades y descansa en la teoría hegeliana, pues, Marx afirmó que gran parte de sus ideas provienen del pensamiento de Hegel, ya que su ideología se desarrolló desde estas bases, pero también hay reflexiones e ideas retomadas de Schelling. ${ }^{5}$

\footnotetext{
${ }^{3}$ Lucio, C. (1977). El Marxismo y Hegel. Mexico, Ed. Grijalbo, p. 57.

${ }^{4}$ Ibid., p. 58.

${ }_{5}^{5}$ Somoza, P. A. (1970). El materialismo historico, una socilogía del marxismo, Ed. Eudeba. Argentina, p. 245.
} 
Prueba de la influencia de Hegel es el primer trabajo elaborado por Marx, que lleva por título La crítica de la filosofía hegeliana del derecho, en la que desarrolla sus propias ideas sobre la sociedad bajo la visión de la dialéctica de Hegel, es decir, Karl Marx toma de Hegel el esquema dialéctico de 'Tesis-Antítesis-Síntesis', sin embargo éste no sirve para Marx más que como un modelo para explicar cómo podemos desarrollar el comunismo; para Hegel, las tesis son las ideas seguidas por algunas personas, las Antítesis son las ideas en contra de las ideas sujetas a la tesis, así pues, entre de estos dos conceptos se creaba la dialéctica y como resultado teníamos la síntesis (aufeben), que es la superación de los contrarios, en ésta se une los mejor de ambas partes, es una idea nueva y mejorada. ${ }^{6}$

Ahora bien, para Marx, el modelo de Hegel podía ser aplicarlo de la siguiente manera: La tesis la tomaba como si fuese el 'burgués', la antítesis como si fuera el 'proletariado', este segundo va en contra del primero y se crea una revolución, dando como resultado la síntesis, que en este caso sería el comunismo. En pocas palabras, podemos decir que Marx invertía la postura de Hegel, para poder ejercer una filosofía práctica en la que construiría una dialéctica en torno a la materia, no a la idea, cuya finalidad no será la simple teorización y justificación de la realidad, sino su transformación revolucionaria. ${ }^{7}$

Por tal motivo Marx, consideraba a la dialéctica no simplemente como teoría, sino también como método de conocimiento y como guía para la acción; la ley general del desarrollo nos da una interpretación justa del pasado para comprender acertadamente los hechos que están sucediendo y analizar las posibilidades en el futuro, por tal motivo es necesario tener en cuenta que la teoría es un factor importante para la acción del porvenir.

${ }^{6}$ Ibid., p. 256.

${ }^{7}$ Ibid., p. 257. 


\section{Marx y la praxis revolucionaria: el Materialismo Dialéctico}

Marx no vive toda su vida repitiendo a Hegel, sino que, por el contrario, desarrolló una nueva teoría filosófica que podría ser llevada a la práctica, el concepto fundamental que Marx toma de Hegel es el de la negación en la historia, esto es como analizamos anteriormente, la dialéctica. Marx, como una idea original, asocia este concepto de negación con una determinada clase social, el proletariado, pues son los obreros los que negarán a la burguesía, es decir, combatir por medio de una revolución el orden burgués, lo va a superar y va a instaurar una sociedad sin clases sociales, una sociedad a la que Marx llamaría comunista, sería una sociedad en la que no exista explotación del hombre por el hombre, y eso es lo que va a llevarnos a su concepto de negatividad ${ }^{8}$ que siempre estará ligado a la praxis del proletariado, pues es el obrero el que va a ejercer la negación sobre la burguesía y de esa negación se podrá llegar a una nueva instancia, es decir, el tercer momento de la dialéctica hegeliana, la conciliación, a esa nueva instancia, es lo que Marx llamará comunismo, que consiste en que las clases sociales abran de superarse y ser dejadas atrás, para que se instaure una sociedad sin explotados y sin explotadores. ${ }^{9}$

Debemos determinar que en el pensamiento Marxista, para que exista una acción, primero debe de ser la teoría; debe hacerse una práctica reflexiva, que implique que no puede existir práctica sin teoría y, del mismo modo, no puede aplicarse una teoría sin práctica, en otras palabras, es lo que aprendemos y el cómo se debe aplicar, y aplicar lo que hemos aprendido, en términos marxistas, no se puede hacer otra cosa más que realizar una revolución y no dejar de pensar en ella, pero pensar en la revolución es que vamos a hacerla; la revolución es la teoría y la práctica, unidas en una síntesis que conoceremos como 'praxis revolucionaria', ninguna práctica, puede ser irreflexiva, los fundamentos teóricos son los que sustentan la acción del pensamiento Marxista y, precisamente, nos dan las herramientas y esquemas prácticos que orientan la acción, de tal manera que una buena revolución actúa de acuerdo al saber teórico y

\footnotetext{
${ }^{8}$ Entendemos negatividad como la antítesis que va en contra de la tesis.

${ }^{9}$ Lucio, C. (1977). Op. Cit., p. 43.
} 
reflexionado y una vez actuado, forma parte de haberlo madurado antes de actuar, para, intentar de tal forma, perfeccionar los resultados a los que se quiere llegar. ${ }^{10}$

Como filosofía práctica, la teoría marxista apunta a la revolución proletaria que entendemos como el pensamiento revolucionario entre clases sociales y, éste, es la base fundamental de la filosofía marxista, ${ }^{\mathrm{II}}$ así tenemos que la situación excepcional que Marx tiene en la historia del saber humano consiste en que, al fundar esta nueva filosofía, la filosofía del cambio social revolucionario, creó, al mismo tiempo, otra disciplina teórica con fines prácticos: El materialismo dialéctico. En este nuevo modelo de análisis histórico señaló que, para lo único que ha servido la filosofía es para entenderse a sí misma; por lo que propone que ahora se debe avanzar y tratar de evaluar las situaciones sociales mediante un enfoque filosófico, examinar el desarrollo de estos fenómenos como algo constante, mostrar que siempre existen cambios que pueden aparecer de forma repentina, lo que implica considerar a las sociedades como algo que se renueva y se desarrolla, sitios en donde existe lo bueno y lo malo, el pasado y el futuro, algo que caduca pero no muere, sino que se desarrolla. Además, un elemento característico en todas las sociedades es que existen y luchan al interior de ellas fuerzas opuestas cuyo criterio de unidad y separación está marcado por su capacidad económica y su propiedad privada, conforme ésta disminuye de un lado y crece del otro se genera un conflicto $y$, con ello, luchas que buscan reestablecer un orden justo mediante una revolución. Esto es en esencia el pensamiento marxista y a través de él se crea una nueva idea aplicable en la sociedad. ${ }^{12}$

De este modo la filosofía marxista será práctica, concreta y real, cambiará totalmente a la política, por medio de la acción revolucionaria y a las demás prácticas sociales concretas. Con esto podemos decir, que antes de Marx, el principal objetivo de la filosofía era expresar la esencia humana, es decir, los ideales humanos con que los

\footnotetext{
${ }^{10}$ Ibid., p. 44.

${ }^{11}$ Cada clase social tiene un determinado interés que, según el materialismo histórico de Karl Marx, están dispuestas a defender, es cuando se crea un conflicto, y se comienza a pensar en una revolución.

${ }^{12}$ Cfr. Blackburn, R. (1978). Teoria Marxista de la revolución proletaria. Ed. Serie Mayor, p. 33.
} 
hombres reflexionan acerca de su naturaleza. Con Marx, la filosofía pasará a ser la realización de esos ideales. En este sentido el pensador alemán afirmaba lo siguiente: "Así como la filosofía halla sus armas materiales en el proletariado, del mismo modo el proletariado encuentra sus armas intelectuales en la filosofía". ${ }^{13}$

Esto quiere decir, que la revolución que Marx pretendía lograr dentro de una sociedad, forma parte de una revolucion teórica y una práctica. La primera se relaciona con el estudio del devenir diálectico, propio de la historia humana, el segundo mediante la realización práctica consciente de una revolución, basada en una lucha de clases. También podemos sostener que ésta necesita un desarrollo práctico político, de tal manera que surge así un nueva nueva teoría que sirve para el estudio del cambio de la realidad social desde las posiciones de la clase obrera que se encuentran profundamente interesadas en una transformación, desde la misma base revolucionaria.

\section{Pensamiento Marxista en práctica}

Para pensar mejor la revolución que Marx proponía, es necesario entender las dos revoluciones que se pueden dar dentro de un estado, en él, existen revoluciones políticas y revoluciones sociales. Las primeras, son aquellas que tienen un cambio más radical y amplio de las leyes del estado, es decir, consisten en que el pueblo tome el poder político y que las clases oprimidas pasen al primer mando, desplazar una clase por la otra, en este tipo de revolución el núcleo principal del problema es el poder. Las segundas, las revoluciones sociales, exigen un cambio total de la sociedad, la diferencia de clases, la economía, y su estructura, de tal manera que el cambio que Marx pretendía lograr, era una revolución comunista, en la que Marx propone que ésta no se trata de la toma del poder político, sino que, transformándose, en su totalidad, la sociedad tendrá necesariamente un cambio en el poder. ${ }^{14}$ Esto quiere decir, que una

\footnotetext{
${ }^{13}$ Ibid., p. 35

${ }^{14}$ Expandir la revolución hasta los cimientos de una sociedad era la forma más efectiva de un cambio total.
} 
revolución social requiere un cambio político, no se trata de dos fases diferentes, sino que están relacionadas, y que finalmente el nuevo desarrollo social terminará por dejar atrás la revuelta política, de tal manera que podemos analizar cómo es que el pensamiento de Marx, tiene bases práctico político. ${ }^{15}$

Bien podemos determinar que el pensamiento marxista descansa en bases teóricas, con fines prácticos, ello nos propone que debemos analizar las diferentes posturas que el pensador alemán presentaba a la Europa de su época, aunque, con el pasar del tiempo se han generado diversas teorías equívocas del Marxismo, por ejemplo; una idea marxista errónea, expone que, Marx decía que, amplificar el sueldo de los obreros acabaría con la desigualdad social. Esto fue mal descifrado, pues el burgués comenzó a argumentar que el salario acrecentado estimula un aumento más rápido de la población obrera, aumento que prosigue hasta que el mercado de trabajo se sobresatura, es decir, hasta que el capital se vuelve insuficiente con relación a la oferta de trabajo, el salario tendría que disminuir radicalmente además de generar una gran cantidad de despidos de modo que, la gran población obrera estaría generando un caos por la disminución de su salario y la pérdida de sus trabajos, esto estaría formando un retroceso al comienzo del aumento del salario, pero con más obreros en desacuerdo y desempleados, los pocos obreros que conserven su trabajo, estarán siendo forzados a cubrir turnos dobles para volver a adquirir el salario que anteriormente tenían y de esta manera el burgués estaría nuevamente sobreexplotando al proletariado, se estaría generando un círculo en donde el dueño de las grandes empresas siempre sería el beneficiario, sin embargo, esta no era la idea principal de Karl Marx, sino que, él exponía que si se reducía el material creado por el burgués, el obrero sólo adquiriera lo necesario, se lograría una equidad social; por ello tenemos que una de las ideas principales de Marx era la justicia social económica y, certificaba que el hombre tiene que vivir sólo con lo que necesita, sin excesos, de tal manera se

\footnotetext{
${ }^{15}$ Sánchez, A., Ensayos marxistas sobre filosofía e ideología. Editorial Océano, Barcelona. p. 53.
} 
estaría eliminando la diferencia de clases sociales y no habría injusticias del hombre por el hombre. ${ }^{16}$

La forma en como Marx exponía sus ideales de la sociedad proletaria, debía de ser una manera en la que pudieran acceder todos a su información y que no transcurrieran ideas erróneas, como la anteriormente mencionada.

\section{Marx y Engels por la liga de los comunistas}

El manifiesto del partido comunista o, como comúnmente se le conoce, Manifiesto comunista,', es una obra redactada por Marx y Engels, en I848, durante casi un año de conferencias y discusiones con los miembros de la Asociación Cultural De Obreros Alemanes. Esos trabajadores, alemanes, eran principalmente artesanos especializados y motivados por la gran expansión capitalista que se estaba generando en aquellos años. En 1836, los artesanos, en un principio, se habían organizado para crear lo que sería una revolución clásica, es decir, liberarse de la opresión de las grandes empresas y unirse como trabajadores, buscaban que se respetaran sus derechos como hombres y como ciudadanos, este movimiento obrero había tomado las bases de los 'Cartistas ingleses' que fue uno de los primeros movimientos importantes de obreros, en contra del poder político de su contexto histórico: Revolución política, buscaba alcanzar ese poder y usarlo a favor de los trabajadores, desarrollando una ideología de clase obrera en contra de la ley de pobres, sin embargo, ambos movimientos eran controlados por la asociación cultural. ${ }^{18}$

Los artesanos fundaron una organización llamada La liga de los justos, que en concreto, era una organización obrera que se enfrenta al reformismo mientras este movimiento aun no era lo suficientemente revolucionario $y$, no tenía el poder suficiente para desarrollar una importante revolución, Marx y Engels entablaban

\footnotetext{
${ }^{16}$ Lucio, C. (1977). Op. Cit., p. 167.

17 Marx, K. Engels, F. (1948). Manifiesto comunista 1848-1948. Traducción del Alemán por Mauricio Amster. Ediciones del centenario. Babel. Chile. Este es un ejemplo de los centenares de ediciones que se han impreso del escrito.

${ }^{18}$ Mayo, B. (1986). Introduccion a la teoría Marxista. Editorial Trillas. México, p. 59.
} 
relaciones con todas las organizaciones obreras que buscaran liberarse de los altos mandos, así pues las ideas de Marx llegaron hacia esta organización, sus ideas comenzaron a tomar importancia dentro de la misma y comenzaron a planear una revolución industrial, de tal manera que un pensamiento reflexivo era la base para que el movimiento obrero fuera posible. Las principales ideas de la liga de los justos se adhiere a la filosofía marxista, de tal manera que, adoptando el pensamiento de Marx, esta organización se convertiría en el primer partido comunista y comenzaría a tomar fuerza. ${ }^{19}$

En 1840 se integraron a dicho movimiento Karl Marx y Friedrich Engels, quienes harían los primeros congresos para un nuevo partido, ellos, generarían un cambio para esta liga, pues las condiciones a las que esta corriente estaba sujeta no fueron aceptadas por los dos pensadores, se oponían a la concepción comunista de esta liga, de tal manera que propusieron, con éxito, una nueva organización en junio de I847; así La liga de los justos cambiaría su nombre a La liga de los comunistas, y se convertiría en una asociación obrera internacional que, naturalmente, dadas las condiciones de esa época, no podía no existir, sino en secreto. ${ }^{20}$

El nuevo partido comunista se crea con base en El Manifiesto Comunista, contiene inéditas visiones del proletariado y de la burguesía, la diferencia de clases sociales y se cuestionó, cómo es que la historia se basa en una producción económica, así como que cada sociedad depende de cada época histórica, llegando a señalar que siempre se genera una lucha de clases, entre explotados y dominantes. El escrito está sencillamente redactado, pues se esperaba que el principal lector fueran las grandes masas obreras a las que iba dirigido, ya que eran personas con bajo nivel de educación, por lo tanto, estaban humildemente escritas las ideas expuestas en él. Marx y Engels hicieron un cambio en la mayor parte de La Liga de los justos y de igual manera cambiaron el lema de la antigua organización; 'Todos los hombres son hermanos' se

\footnotetext{
${ }^{19}$ Blackburn, R. (1978). Op. Cit., p. 47

${ }^{20} \mathrm{El}$ motivo de mantener un movimiento obrero en secreto se debe al poder de la burguesía para poder frenar dichos movimientos y por consecuente la acción de la revolución.
} 
sustituye por el revolucionario: ‘Proletarios de todos los países: uníos!'. Con esto, podemos decir que aquel que quisiera formar parte de esta organización tenía que tener los mismos intereses, deben de estar unidos, se distinguirían por hacer referencia en el provecho de cambiar su condición social, así pues, el nuevo grupo de comunistas, quería decir que habría y debería haber solo un partido original del proletariado revolucionario, y que este fuera único en todos los aspectos, que la filosofía comunista fuera la base fundamental para enfrentar al burgués, por lo tanto podemos afirmar que Marx siempre ha supuesto un solo partido comunista, en el que todos los oprimidos del mundo puedan acceder al mismo. ${ }^{21}$

La nueva liga tenía que tener una constitución democrática, pues, para Marx un elemento fundamental era la burocracia, es la mejor manera de administrar una sociedad, es fundamental en un determinado grupo de personas para ponerse de acuerdo en las actividades que a cada individuo le convenga, sin embargo, los altos mandos que la componen son en ocasiones individuos sin la capacidad de cumplir completamente con las actividades que se les han otorgado, y si no se cumple tal tarea entonces se estaría generando un problema social, que en este caso es la desigualdad entre los individuos de alguna determinada sociedad. ${ }^{22}$

En el pensamiento de Marx, la burocracia no fomenta la creación de la riqueza, pero si es quien la controla, pues es por medio de impuestos y leyes en donde se maneja gran parte de la riqueza de una sociedad, y estas riquezas son desproporcionadas dentro de la misma población, además esta nueva organización revolucionaria debía contar con funcionarios cuidadosamente elegidos y congresos anuales y de igual manera por razones de seguridad la liga tenía que ser secreta, pero también tenían que utilizarse al máximo todas las estrategias de organización y de propaganda pública, para que cada vez más ciudadanos oprimidos que quisieran liberarse, pudiesen afiliarse a La Liga De Los Comunistas. ${ }^{23}$

\footnotetext{
21 Sánchez, A. (1983). Op. Cit., p. 67

22 Blackburn, R. (1978). Op. Cit., p. 41

${ }^{23}$ Ibid., p. 42.
} 


\section{El interminable sueño Marxista}

La liga de los comunistas en 1848 al principio no funcionó de la manera en como lo abrían deseado Marx y Engels, pues, la organización era demasiado reciente para generar un cambio social tan radical, algunos de sus integrantes regresaron a Alemania para seguir por su propia parte con la revolución obrera, unos cuantos se unieron en pequeños grupos de revolucionarios, mientras que los miembros que se quedaron en la liga de los comunistas, argumentaban que era necesario hacer notoria la organización, y hacer un trabajo de actividad pública, mover por medio de las ideas a la clase proletaria para generar un despertar revolucionario, esto en un principio convenció a Marx y Engels, por lo que creían que era necesario reagrupar a los integrantes de la liga para tomar medidas más radicales que no se habían tomado hasta ese momento para lograr una revolución proletaria.

En I850 Marx y Engels exponen la praxis en que debía de funcionar la liga de los comunistas, enfocándose en una revolución proletaria, con más fuerza que nunca, pues la revolución por una parte había tenido una pausa, los pequeños burgueses trataron de calmar la revuelta obrera, ofreciéndoles un mejor salario y un vivir más beneficioso, otorgando trabajo por medio del estado, para Marx, ésto era desviar la atención revolucionaria de los obreros con estas supuestas mejoras laborales, y que esto solo será un florecimiento temporal. ${ }^{24}$

Los burgueses necesitaban poner fin a la revolución, tener a todo un pueblo en contra no era beneficioso para el mismo burgués, con esto podemos decir, que, el poder del Estado se estaba dando cuenta de que realmente los trabajadores podrían derrocar la montaña de plusvalía en la que se encontraban, gracias al proletario, y que ellos mismos propondrían las nuevas leyes para desarrollar una sociedad sin distinción de clases; un pueblo en lo que todo sea justo para los justos, ni más ni menos para nadie. Mientras que, los propietarios de las grandes riquezas del Estado analizaban

${ }^{24}$ Ibid., p. 20. 
cómo detener la revolución obrera, con premios y beneficios, ${ }^{25}$ el proletariado más claramente daba cuenta de que su revolución, poco a poco, estaba funcionando al obtener estos mínimos beneficios, es cuando Karl Marx, se percata que no es el momento de conformarse con pequeñas mejoras como las ofrecidas hasta ahora por el burgués, sino que la revolución no debe de parar hasta obtener los resultados deseados por la liga de los comunistas, es decir, para Marx, la sintesis aún no había llegado a su etapa final, sino que, estaba aún en confrontacion la tesis contra la antitesis. $^{26}$

En I850 Karl Marx ofrece un discurso, en el que expone y motiva a los obreros asociados a la liga de los comunistas a continuar con la lucha, que esta no se detuviera, pues era el preciso momento donde sus ideales estaban tomando mas fuerza que nunca, en dicho discurso expone lo siguiente:

Nuestros intereses y nuestras tareas consisten en hacer la revolución permanente hasta que haya quedado descartada la dominación de las clases más o menos poseedoras, hasta que el proletariado conquiste el poder del estado, hasta que la asociación de los proletarios se desarrolle, y no solo en un país, sino en todos los países predominantes del mundo, en proporciones tales, que cese la competencia entre los proletarios de estos países, y hasta que por lo menos las fuerzas decisivas estén concentradas en manos del proletariado. ${ }^{27}$

Aunque si bien, sabemos que la revolución proletaria ya había comenzado, y está necesitaba cambiar cuanto antes, un grupo de La liga de los comunistas, establecían que debían de tomar con toda fuerza la revolución hacer un cambio repentino en la misma, es decir tomar el control de una vez por todas o acabar con la lucha en ese momento y rendirse, sin embargo para Marx, esto no podía funcionar de tal manera, sino que había que apegarse a las teorías de la revolución y no perder el sentido en el desarrollo revolucionario, debían seguir con la lucha constante, pues la preocupación del pensador alemán, era que, para que el proletario pudiese lograr una revolución completa, ésta debía de tener una serie de luchas de clases, en las que con el tiempo, el

\footnotetext{
${ }^{25}$ Algunos dueños de fábricas comenzaron a otorgar alimentos y áreas de trabajo más confortables para los obreros.

${ }^{26}$ Blackburn, R. (1978). Op. Cit., p. 21.

${ }^{27}$ Marx, K. (1946). El capital. Editorial Fondo de Cultura Económica, Máxico, p. 325.
} 
proletario, podría darse cuenta de su situación y su lugar en la sociedad, comprender su parte política y, dominarla, para lograr un cambio completo, es necesario entender las contradicciones a las que se quiere enfrentar. ${ }^{28}$

De tal manera podemos demostrar que la intención de Marx, era hacer totalmente el cambio radical pero con su debido tiempo, descubrir que, las clases obreras, al ser ajenas a su condición, no podían darse cuenta por sí mismas, en un tiempo breve, que no era humana la explotación que estaban sufriendo, Marx expone que el obrero bebía de darse a notar, es decir, que todo el mundo se enterará de su posición revolucionaria, y que, con esto, el burgués terminara por retroceder y acceder a tomar el cambio social, no como opción, sino como una exigencia de la clase proletaria, sin embargo, ésta lucha constante de sociedades no es determinada por Marx, sino que ésta lucha siempre tiene que estar presente para poder desarrollar otro tipo de sociedades. Para Marx, el motor principal de la humanidad son los cambios que existen dentro de una sociedad, y para que una comunidad cambie, es necesario encontrar algo que la confronte, para así lograr una revolución y poder generar una nueva colectividad, reconstruida con dos partes opuestas, Marx en este caso, deseaba que los trabajadores, asociados a la Liga de los comunistas, fueran políticos independientes, seleccionados rigurosamente para que fueran capaces de poder transmitir las ideas de todos los obreros explotados. ${ }^{29}$

\section{La filosofía práctica marxista en el México Contemporáneo: Enajenación laboral en México}

Actualmente, las obras de Marx se consideran, por algunos, de poca relevancia, se piensa que sus escritos no cuentan con una preeminencia o conclusión que tenga algo que decir respecto al mundo moderno, esto se debe a que existe una amplia ignorancia, e ideas erróneas, de los mismos escritos de Marx, por consiguiente, resulta también la ignorancia respecto a los trabajos actuales marxistas. Sin embargo debemos saber que

\footnotetext{
${ }^{28}$ Marek, F. (1973). Filosofía y revolución. Editorial Nuestro Tiempo. México, p. 89.

${ }^{29}$ Ibid., p. 92.
} 
el pensamiento Marxista tiene la capacidad para volver a la actualidad con cada desacuerdo entre obrero y patrón y, que se manifiesta en cada crisis económica mundial, pensar y analizar cuidadosamente qué es lo que Marx pretendía lograr con sus obras: El manifiesto comunista y El Capital; en este último, Marx, detalla el sistema económico capitalista de Alemania del siglo XVIII, desde sus orígenes hasta un final predecible, es comprendido de materias entre las que se encuentra la economía, la historia, la política y la filosofía. ${ }^{30}$

Es necesario saber que la riqueza o el capital económico es quien sigue controlando en la mayoría de las acciones políticas del globo terráqueo, y es difícil, que el proletariado, en la actualidad, realice una revolución como se generó en los años de vida de Karl Marx, además de que la burguesía, siempre tiene el control en todas las decisiones, no obstante mencionar a México no es la excepción, pues actualmente en el territorio mexicano se determina que la gran explotación laboral es un problema en el que se enfrentan la mayoría de los ciudadanos mexicanos y además, siempre, que existe una crisis económica, los más afectados son los obreros, aunque haya programas de apoyos económicos, estos siempre son manejados por la política, que a su mismo tiempo es controlada por los burgueses, es decir, ambos son aliados para beneficiarse entre ellos, y dejar, al que tiene menos, con cada vez menos, por ejemplo; alguna empresa necesita tener un permiso para laborar en un cierto territorio, el líder de cierto territorio, trata de llegar a un acuerdo con la empresa, está misma ofrece empleos para las personas de dicha zona, además de una gran inyección económica para el estado, será beneficioso para los lugareños, el dirigente de dicho espacio, provee el territorio con tal de que los integrantes de su sociedad tengan un empleo para subsistir, sin embargo, la empresa, seleccionó ese lugar no sólo porque quizá le parecía conveniente el espacio, sino que, la verdadera intención es pagar un salario injusto por la fuerza de trabajo; sabemos que en México las desigualdades económicas se observan todos los días, en todos lugares, y esto se genera cuando el obrero siente

\footnotetext{
${ }^{30}$ Feuerbach, L. (1969). La filosofía del futuro. Editorial Calden. Argentina. p. 55.
} 
que es justo lo que no está recibiendo por su fuerza laboral, vende su tiempo y esfuerzo por una determinada cantidad de dinero, es necesario saber la razón principal de esta enajenación laboral. ${ }^{31}$

Explicaremos aquí, el pensamiento de Marx sobre la explotación laboral. El objetivo del capitalista es generar la mayor parte de ganancias, capital o riquezas, es decir, el patrón, de alguna determinada empresa, busca siempre generar mayores ganancias para sí mismo, para lograrlo, el empresario produce un bien o servicio y lo vende obteniendo una ganancia, con esto podemos determinar, que el capitalista se las ingenia para poder generar más bienes económicos personales a través de un proceso de elaboración de productos; lo que determina en qué cantidad, el patrón podrá vender sus servicios o productos, es la cantidad de trabajo de lleva realizarlo, es aquí, cuando entra el obrero, pues es quien trabaja agregando el valor al producto, con esto determinamos que el obrero vende su trabajo a cambio de un salario, y dependiendo de la labor y de la materia que cueste elaborar un producto, es lo que le da valor en el mercado, el empresario obtiene su ganancia, usando materiales económicos para generar artículos caros y de fuerza de trabajo barata para transformar esa materia en algo costoso, aquí se crea una desigualdad dentro de la empresa, porque dentro de este proceso, del mercado, existe una gran parte del trabajo que no le pagan al obrero, es decir, si el valor de un producto equivale al tiempo de trabajo invertido en él, entonces el valor de cambio de la jornada de trabajo es igual a su producto, el salario debe ser igual al producto de trabajo, pero sabemos que en realidad esto no es aplicable por los capitalistas, pues, supongamos que un obrero tarda ocho horas en elaborar diez productos, y cada producto sale a la venta en veinte monedas de plata, el total de esa mercancía tendría un valor de doscientas monedas de plata, lo cual, supuestamente estas doscientas monedas de plata, es el valor de las materias primas y del trabajo del obrero, sin embargo esta plusvalía, no le pertenece y es el dueño de la empresa el que decide cuantas monedas de plata le tocan al proletariado, abusando así pues, de su

${ }^{31}$ Ídem, p. 60. 
condición social y económica, en donde probablemente podría otorgar, solamente, veinte monedas de plata, ${ }^{32}$ equivalente a un producto de los diez elaborados. ${ }^{33}$ Es cuando el proletario acepta su condición económica y siente que ese trato es justo, es decir, la plusvalía que genera el obrero es el valor del trabajo no remunerado para el asalariado, y esta ganancia se la queda el capitalista, esto se genera con la duración excesiva de la jornada de trabajo que crea aumento en la productividad, con esto podemos decir que la base de la plusvalía es la explotación capitalista, y esta aumenta cuando el trabajador la asume como algo que pertenece a su condición humana. Para Marx este es un trato injusto en donde el obrero es explotado y, además, mal remunerado. ${ }^{34}$

\section{De la teoría a la práctica en México}

En la actualidad las dimensiones de clases sociales son muy notorias en el territorio mexicano, y es cuando debemos de ponernos a razonar la praxis marxista para un mejor intercambio de vienes económicos, es decir, pensar en un salario equitativo para todos los ciudadanos, es una idea que podriamos descartar de las leyes del trabajo en méxico, ${ }^{35}$ pues sabemos que en el territorio nacional existe una cantidad de salario que como mínino todo trabajador debería de recibir, no obstante, por el esfuerzo de algunos es que este ingreso se incrementa, pues no podemos pensar en la misma cantidad de dinero de un obrero, a alguien que se preparó para ser un ingeniero, por ejemplo; es necesario admitir, que el burgués tiene derecho a siempre obtener mayores ganancias, pues es absurdo pensar, que una persona que se esmeró toda su vida, en poner una fábrica gane lo mismo que una persona que nunca tuvo el menor interés por emprender, además de que el capital, no solo paga los salarios del proletario, sino que también tiene que pagar diversos factores más, como tierra, agua, energías, etc.

\footnotetext{
32 El burgués, se queda con la mayor parte de ganancia, y puede multiplicar su inversión gracias al obrero.

${ }^{33}$ Gamble, A. (1985). El capitalismo en crisis, la inflación y el estado. Editorial Siglo XXI. México, p. 119.

34 Ibídem., p. 119.

35 Las leyes laborales otorgan a los empleados el derecho de formar sindicatos; también permiten que empleados y empleadores participen en determinadas actividades.
} 
pero ¿cómo es entonces que se crea una gran diferencia de clases sociales cuando hablamos de economía? Para contestar esta pregunta debemos de analizar la posible solución desde la teoría marxista, para Marx, el primer paso era eliminar el sistema político ya existente, y crear una sociedad comunista desde el comienzo, esto a través de la lucha de la unidad de los trabajadores para dar paso a una comunidad más justa, sin explotadores ni explotados.

Con esto se busca eliminar la propiedad privada y que todo fuera de todos y para todos, aunque si bien ya analizamos que es injusto que el emprendedor de alguna empresa gane lo mismo que una persona que nunca aportó nada a la misma, también es injusto que el capitalista se aproveche de las necesidades del hombre sólo porque sabe que esté tiene que sobrevivir, y llevar algún sustento a su casa; es aquí cuando podemos determinar, que si el burgués no fuera tan ambicioso, podría generar mayores salarios para los mismos obreros, y, estos, por ende, no tendrían que sufrir explotación alguna para poder cubrir sus necesidades cotidianas, pues, algunos trabajadores se ven en la necesidad de cubrir turnos laborales extras para alcanzar un salario que les permita tener una vida digna, por decirlo en pocas palabras, que el dueño de alguna determinada empresa, debería de pagar justamente a los trabajadores, en lugar de que el mismo burgués tenga que quedarse con el doble de las ganancias, y así podrían implementar un nuevo sistema en el que se modifiquen las leyes del trabajo en el territorio mexicano, para que puedan beneficiar a una gran mayoría y así comenzar a generar una sociedad más justa, en la que el trabajador obtenga más ganancias de los productos que él mismo elaboro. Un ser humano, realmente, solamente necesita una cierta cantidad de mercancías para vivir, lo que se produce de más, es sobrante y le hace falta, quizá, a otro hombre que busca o necesita para sobrevivir, de tal manera que, como apunta Karl Marx, el hombre solo debe de vivir con lo necesario y, de tal manera, ser equitativo en el aspecto económico, es beneficioso que no existieran ciudadanos que tengan mucho, porque existen otros que tienen pocos, y ello ocurre por la mala y no equitativa repartición de la riqueza. 


\section{Conclusión:}

Podemos concluir que el marxismo propone diversas teorías aplicadas a las sociedades, y a los intereses históricos de las personas que siglos atrás se veían obligados a vender su fuerza de trabajo a los Burgueses. Sabemos que Karl Mar luchaba por el comunismo, pues creía que con esto podría cambiar la calidad de vida de los obreros de su época; con él entendimos que la estructura social se encuentra dividida, por un lado, por los burgueses capitalistas y, por otro lado, por las fuerzas productoras, que son los obreros, estas son dos clases sociales muy distintas, una es la que genera riquezas y la otra la que se apropiaba de ellas, por tal motivo Marx pensaba que no era justo que los obreros, quienes desempeñaban las labores más fuertes, no fueran bien pagados, mientras que los burgueses sólo pensaban e imponían sus exigencias y recibían las grandes ganancias.

Con el pensamiento Marxista podríamos comenzar a analizar las sociedades y nuevamente proponer acabar con la explotación laboral que se vive aún, es decir, podemos hacer algo contra las malas condiciones laborales que sufren los obreros, actualmente, condiciones que no son sino el reflejo mismo de años de aprovechamiento la historia de la humanidad de unos sobre otros; sin embargo considerando los ideales de Karl Marx, podríamos generar un nuevo pensamiento en el que el ser humano, rico, poderoso, bien posicionado económicamente, pueda sensibilizarse de la situación, y eche un vistazo hacia donde se encuentra el ser humano menos beneficiado, explotado, poco posicionado económicamente y se haga una mejor sociedad, más justa e igualitaria. 